\title{
Fecal incontinence in pregnancy and post partum
}

\author{
Cynthia Brincat $^{\mathrm{a}, \mathrm{b}, *}$, Christina Lewicky-Gaupp ${ }^{\mathrm{a}, \mathrm{b}}$, Divya Patel ${ }^{\mathrm{b}}$, Carolyn Sampselle ${ }^{\mathrm{a}, \mathrm{b}, \mathrm{c}}$, Janis Miller ${ }^{\mathrm{a}, \mathrm{b}, \mathrm{c}}$, \\ John O.L. DeLancey ${ }^{a, b}$, Dee E. Fenner ${ }^{a, b}$
}

a Pelvic Floor Research Group, University of Michigan, Ann Arbor, MI, USA

b Department of Obstetrics and Gynecology, University of Michigan, Ann Arbor, MI, USA

c University of Michigan School of Nursing, Ann Arbor, MI, USA

\section{A R T I C L E I N F O}

Article history:

Received 2 February 2009

Received in revised form 23 March 2009

Accepted 24 April 2009

\section{Keywords:}

Anal incontinence

Fecal incontinence

Pregnancy

Vaginal delivery

\begin{abstract}
A B S T R A C T
Objective: To assess the prevalence of fecal incontinence (FI) during pregnancy and post partum, and to determine any associations with demographic and birth variables. Methods: Secondary analysis of 240 primiparous women conducted during pregnancy and post partum. Women were asked at various time points if they had lost control over their stool or bowel movements, and if they were practicing Kegel exercises. Associations of bowel symptoms with demographic and birth data were evaluated. Results: Most participants were white (87\%), with a median age of 30 years (range, 18-42 years). Women who reported fecal incontinence at 1 year were more educated than those who did not report it. No other demographic or birth data were associated with fecal incontinence at 1 year. Conclusions: Prevalence of FI during pregnancy and post partum is low and not linked to low-risk birth. Furthermore, when FI occurs it is often sporadic. This should be reassuring to patients and providers alike.

(c) 2009 International Federation of Gynecology and Obstetrics. Published by Elsevier Ireland Ltd. All rights reserved.
\end{abstract}

\section{Introduction}

Fecal incontinence (FI) is a devastating problem. A large population-based study of 7000 participants found that $2.2 \%$ of individuals reported incontinence of solid or liquid feces; female sex was an independent risk factor for incontinence [1]. Women are nearly twice as likely as men to report FI that is moderate to severe [2] and it is well known that vaginal birth can cause significant trauma to the anal sphincter [3], potentially explaining this sex-based discrepancy.

There have been many studies concerning the risk of FI in the context of anal sphincter injury and childbirth [4-6]. However, it is well known that many women with sphincter injuries are continent and some women with intact sphincters have fecal incontinence, suggesting that other factors must be involved [7]. There are few prospective studies that assess women's symptoms throughout pregnancy and post partum; most are limited in their longitudinal followup. Long-term follow-up is crucial because the pelvic floor has not fully recovered its strength even at 6 weeks post partum. The aim of the present study was to assess the prevalence of FI during pregnancy and post partum as well as to explore associations with demographic and birth variables by querying women about their symptoms of fecal incontinence from mid-pregnancy up to 1 year post partum.

\footnotetext{
* Corresponding author. Division of Female Pelvic Medicine and Reconstructive Surgery, Department of Obstetrics and Gynecology, L4100 Women's Hospital, University of Michigan Medical Center, 1500 East Medical Center Drive, Ann Arbor, MI 48109-0276, USA. Tel.: +1734 474 4035; fax: +1734936 8745 .

E-mail address: cbrincat@med.umich.edu (C. Brincat).
}

\section{Materials and methods}

This was a secondary analysis of a randomized controlled trial of 240 primiparous women during pregnancy and 1 year post partum. The primary aim of the parent study was to determine the effects of prenatal perineal massage and pushing style in the second stage of labor on pelvic floor function at several time points. The study compared: (1) women who had been instructed to push when they felt the urge (spontaneous pushing), with or without perineal massage instruction, constituting the full intervention group; (2) women who received routine care during labor, which typically meant they were instructed to start pushing once their cervical dilation was determined to be complete (some of these women had received instruction in perineal massage and some had not); and (3) women who received neither encouragement to push spontaneously nor prenatal perineal massage instruction, constituting the control group. The results of this study are not yet in publication.

During the study, women were also asked to answer questions regarding symptoms of $\mathrm{FI}$ at the following time points: 20 and 35 weeks of pregnancy, and 6 weeks, 6 months, and 1 year post partum. Specifically, at each of these time points women were asked, since the last visit, if they had lost control over their stool or bowel movements, and if they were practicing Kegel exercises.

Inclusion criteria were established at telephone screening prior to the first evaluation ( 20 weeks) and were the following: 18 years of age or older; primagravida; less than 20 weeks of pregnancy at time of entry into the study; expected vaginal delivery; expected singleton birth; plans to reside within driving distance of the study center for the first 6 months following the birth of the infant; planning to deliver 


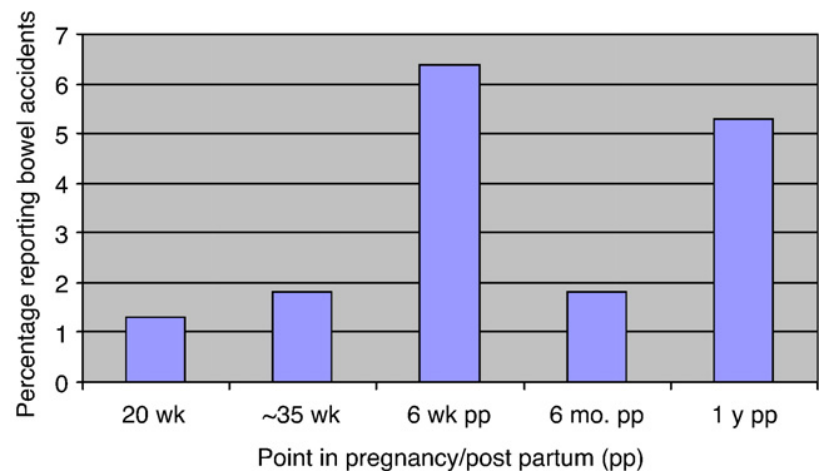

Fig. 1. Percentage of patients reporting fecal incontinence at various time points during pregnancy and post partum.

at the study center or local community hospital; no history of urinary incontinence prior to the pregnancy; and a negative history of chronic urinary tract infection ( $>3$ per year), chronic bowel conditions, spinal cord injury, multiple sclerosis, muscular dystrophy, and cerebral palsy. Exclusion criteria (established during the 20-week evaluation) included evidence of urinary incontinence on exam or an inability to contract the pelvic floor muscles. Associations of fecal incontinence with demographic and birth data were determined using Fisher exact tests for categorical variables and $t$ tests for continuous variables. All statistical analyses were completed using SPSS software version 16.0 (SPSS, Chicago, IL, USA). Differences were considered statistically significant when $\mathrm{P}<0.05$.

\section{Results}

At each time point the women were asked, "Have you lost control over your stools or bowel movements, that is, have you had any bowel accidents?" An affirmative answer was reported in $1.3 \%$ ( 3 out of 240 ) of the cohort at 20 weeks of pregnancy and $1.8 \%$ ( 3 out of 171) at 35 weeks of pregnancy. FI was most common at 6 weeks post partum, where $6.4 \%$ gave an affirmative answer (11 out of 173). At 6 months post partum, 1.8\% (3 out of 169) had experienced FI. Finally, at 1 year post partum, 151 women were ultimately available for follow-up and $5.3 \%$ ( 8 out of 151) had experienced Fl (Fig. 1). Women in the "spontaneous pushing" group were equally likely to have fecal

Table 1

Demographic characteristics of the study population. ${ }^{\mathrm{a}}$

\begin{tabular}{|c|c|c|c|}
\hline \multirow[t]{2}{*}{ Characteristics } & \multicolumn{2}{|c|}{$\begin{array}{l}\text { Fecal incontinence self-reported at } 1 \text { year } \\
\text { post partum }\end{array}$} & \multirow[t]{2}{*}{$P$ value } \\
\hline & Yes $(n=8)$ & No $(n=143)$ & \\
\hline BMI & $27.85 \pm 6.44(\mathrm{n}=8)$ & $24.50 \pm 5.65(n=138)$ & 0.362 \\
\hline Age, y & $29.75 \pm 4.33(\mathrm{n}=8)$ & $30.10 \pm 4.55(n=140)$ & 0.534 \\
\hline Ethnicity & $(\mathrm{n}=8)$ & $(\mathrm{n}=140)$ & 0.858 \\
\hline White & $8(100)$ & $120(85.7)$ & \\
\hline Black & - & $5(3.6)$ & \\
\hline Asian & - & $6(4.3)$ & \\
\hline Hispanic & - & $4(2.9)$ & \\
\hline Other & - & $5(3.6)$ & \\
\hline Education & $(n=8)$ & $(n=139)$ & 0.001 \\
\hline High school & - & $2(1.4)$ & \\
\hline Some college & $2(25)$ & $26(18.7)$ & \\
\hline 4 years college/tech & - & $48(34.5)$ & \\
\hline Graduate school & $6(75)$ & $63(45.3)$ & \\
\hline Income, US\$ & $(\mathrm{n}=8)$ & $(\mathrm{n}=139)$ & 0.06 \\
\hline$<20000$ & $1(12.5)$ & $7(5.0)$ & \\
\hline $20000-40999$ & $3(37.5)$ & $14(10.1)$ & \\
\hline $41000-60000$ & - & $23(16.5)$ & \\
\hline$>60000$ & $4(50)$ & $95(68.3)$ & \\
\hline
\end{tabular}

Abbreviations: BMI, body mass index (calculated as weight in kilograms divided by height in meters squared).

a Values are given as number (percentage) or mean \pm SD unless otherwise indicated.
Table 2

Birth data for the study population. ${ }^{\text {a }}$

\begin{tabular}{|c|c|c|c|}
\hline \multirow[t]{2}{*}{ Variable } & \multicolumn{2}{|c|}{$\begin{array}{l}\text { Fecal incontinence self-reported at } 1 \text { year } \\
\text { post partum }\end{array}$} & \multirow[t]{2}{*}{$P$ value } \\
\hline & Yes $(n=8)$ & No $(n=143)$ & \\
\hline Baby weight, $\mathrm{g}$ & $3647 \pm 554(n=8)$ & $3475 \pm 483(n=137)$ & 0.930 \\
\hline Head circumference, $\mathrm{cm}$ & $33.8 \pm 3.51(n=7)$ & $34.6 \pm 2.20(n=118)$ & 0.252 \\
\hline Mode of delivery & $(\mathrm{n}=8)$ & $(\mathrm{n}=138)$ & 0.868 \\
\hline Cesarean & $2(25)$ & $31(22.5)$ & - \\
\hline Vaginal & $6(75)$ & $107(77.5)$ & - \\
\hline Operative vaginal delivery & $(n=1)$ & $(\mathrm{n}=11)$ & 0.461 \\
\hline Vacuum & 0 & 7 (63.6) & - \\
\hline Forceps & $1(100)$ & $4(36.4)$ & 0.208 \\
\hline $\begin{array}{l}\text { Laceration (no. of vaginal } \\
\text { deliveries) }\end{array}$ & $(n=6)$ & $(\mathrm{n}=107)$ & \\
\hline None & $4(66.7)$ & $52(48.6)$ & - \\
\hline First degree & $1(16.7)$ & $20(18.7)$ & - \\
\hline Second degree & $1(16.7)$ & $41(38.3)$ & - \\
\hline Third Degree & 0 & $13(12.1)$ & - \\
\hline Total & $2(33)$ & $74(69.2)$ & 0.497 \\
\hline Missing & 0 & $6($ total $=132)$ & - \\
\hline Episiotomy & $3(50.0)$ & $23(19)$ & 0.292 \\
\hline Median & 3 & $19(82.6)$ & - \\
\hline Mediolateral & 0 & $4(17.4)$ & - \\
\hline Missing & 0 & $11($ total $=135)$ & - \\
\hline Position of fetal head & $(\mathrm{n}=8)$ & $(n=102)$ & 0.970 \\
\hline Occiput anterior & $7(87.5)$ & $88(86.3)$ & \\
\hline Occiput posterior & $1(12.5)$ & $14(13.7)$ & \\
\hline
\end{tabular}

a Values are given as number (percentage) or mean \pm SD unless otherwise indicated.

incontinence at 1 year (5\%) as those in the other 2 groups (6\%) $(P=0.985)$. Almost all of the women $(86 \%)$ with FI were practicing Kegel exercises at 1 year post partum as were $75 \%$ of the women without fecal incontinence $(P=0.527)$.

Most of the participants were white (87\%), with a median age of 30 years (range, 18-42 years). Women who reported fecal incontinence were more educated than those who did not; there were no other differences seen between these two cohorts with respect to demographic variables (Table 1 ).

There were no statistically significant differences detected in mode of delivery or other birth data between those who reported bowel symptoms at 1 year post partum and those who did not (Table 2). Of those who reported bowel accidents at any time during pregnancy and post partum $(n=23)$, only 4 women reported bowel accidents at more than one time point. Half of the women who reported FI at 1 year post partum reported symptoms at some point in the postpartum period (Fig. 2).

\begin{tabular}{|c|c|c|c|c|c|}
\hline \multicolumn{3}{|c|}{ Pregnancy } & \multicolumn{3}{|c|}{ Postpartum } \\
\hline Case & 20 weeks & 35 weeks & 6 weeks & 6 months & 12 months \\
\hline 1 & & & & & \\
\hline 26 & & & & & \\
\hline 39 & & & & & \\
\hline 65 & & & & & \\
\hline 86 & & & & & \\
\hline 94 & & & & & \\
\hline 97 & & & & & \\
\hline 116 & & & & & \\
\hline 121 & & & & & \\
\hline 145 & & & & & \\
\hline 146 & & & & & \\
\hline 153 & & & & & \\
\hline 166 & & & & & \\
\hline 186 & & & & & \\
\hline 190 & & & & & \\
\hline 198 & & & & & \\
\hline 246 & & & & & \\
\hline 252 & & & & & \\
\hline 533 & & & & & \\
\hline 534 & & & & & \\
\hline 902 & & & & & \\
\hline 905 & & & & & \\
\hline 909 & & & & & \\
\hline
\end{tabular}

Fig. 2. Bowel accidents in women who answered affirmatively that they had a bowel accident at more than one time point during the study period. 


\section{Discussion}

The present study found a low prevalence of women reporting bowel accidents during pregnancy and the postpartum period. Because the prevalence of FI was so low, no significant associations with specific labor events were identified. None of these symptomatic women had known sphincter injuries during delivery, nor were variables regarding birth-including spontaneous pushing or Kegel exercises-associated with FI.

The range of prevalence of postpartum fecal incontinence reported in the literature is large, ranging from 3\%-29\% [4,6,8-12]. The prevalence rates vary greatly depending on the population studied, types of questions asked, how questions are asked, the time from delivery, and the definitions of fecal incontinence. Overall, the present findings are most consistent with the rates of FI during pregnancy and post partum reported by Eason et al. [4], Borrello-France et al. [12], and Chaliha et al. [13]. For example, Chaliha et al. [13], in a cohort of 286 nulliparous women, reported rates of FI at 34 weeks and 3 months post partum to be $3 \%$ and $2.5 \%$, respectively (CI $0.7 \%-6.2 \%$ ). BorrelloFrance et al. [12] reported postpartum FI at 6 weeks and 6 months in a primiparous group of women without sphincter lacerations to be $11.2 \%$ and $8.2 \%$, respectively. They included incontinence of mucous, liquid, or solid stool in their definition of FI. The present study's design, population of primiparous women and time frame for follow-up are similar to the studies of Eason et al. [4] and Chaliha et al. [13]. In contrast, the rate of FI reported in the present study at 1 year postpartum is much lower than that reported by Guise et al. [9] in 2007. This rate is based on a survey of all women in Oregon who delivered over a 6-month period who were then contacted 36 months after delivery. Their reported rate of $29 \%$ is one of the highest rates of postpartum FI in the literature and is likely due to the inclusion of flatal incontinence. If flatal incontinence was removed from their definition, the prevalence of FI would be approximately $15 \%$ and may be additionally explained by the large number of patients included in that study, more operative vaginal deliveries, episiotomies, sphincter lacerations, and obesity in the study population compared with the present study. It is important when evaluating this literature and when counseling our patients that these variables and patient characteristics are considered. The present data would support a low risk of the new onset of bowel control symptoms in a healthy, white, low-risk population with rare operative vaginal deliveries and no gross sphincter lacerations.

The present study showed a sporadic increase in FI at 6 weeks post partum that decreased at 6 months and then increased again at 1 year post partum. Interestingly, half of the women reporting FI at 1 year had postpartum fecal incontinence (at 6 weeks and 6 months). These findings would support close follow-up and consideration for further testing and counseling for women with complaints of FI within the first half year following delivery. At the same time, women should be reassured that symptoms within the first weeks after delivery are likely to resolve and at 1 year from delivery be gone. Longer follow-up of women with transient symptoms may improve our understanding of the increase of FI as we age to determine if childbirth or other factors contribute to the increase in FI later in life.

The increase in $\mathrm{FI}$ at 6 weeks post partum is consistent with reports of urinary incontinence and pelvic floor strength following vaginal delivery [14,15]. The decrease in symptoms at 6 months is also consistent with the recovery and healing of the neuromuscular and connective tissue components of the pelvic floor. The upturn in symptoms again at 1 year would indicate the complexity of fecal continence, and the interaction of other variables, including diet, stooling frequency and consistency, activities, medications, and life- style. Continence of stool is dependent on many factors. It is not surprising to see variability in symptoms over time for any given individual. While difficult, understanding the variability of FI symptoms and the role of vaginal delivery, if any, requires larger, prospective studies of low risk women. The present finding of a sporadic increase at 6 weeks post partum, then again at 1 year post partum indicate the importance of this longer term follow-up and accurate documentation of obstetric variables.

The study has the limitations common to secondary analysis of large, prospective studies. It was powered to detect a difference in outcomes relative to urinary incontinence rather than FI and thus a larger study is necessary to further validate these findings. The present study should also be expanded to include more questions concerning type and frequency of FI, as well as other symptoms such as fecal urgency and bother. In addition as discussed above, this was a low-risk, predominantly white, educated, higher income population and therefore findings may not be generalizable to the general population.

In conclusion, these results indicate that rates of FI during pregnancy and post partum are quite low and not linked to low-risk birth. Furthermore, when FI occurs it is often sporadic. This should be reassuring to patients and providers alike.

\section{Acknowledgments}

We gratefully acknowledge investigator support from the National Institute of Health through grant NIH/NINR (PI:Sampselle) NR04007.

\section{References}

[1] Nelson R, Norton N, Cautley E, Furner S. Community-based prevalence of anal incontinence. JAMA 1995;274(7):559-61.

[2] Drossman DA, Li Z, Andruzzi E, Temple RD, Talley NJ, Thompson WG, et al. U.S. householder survey of functional gastrointestinal disorders. Prevalence, sociodemography, and health impact. Dig Dis Sci 1993;38(9):1569-80.

[3] Fenner DE, Genberg B, Brahma P, Marek L, DeLancey JO. Fecal and urinary incontinence after vaginal delivery with anal sphincter disruption in an obstetrics unit in the United States. Am J Obstet Gynecol 2003;189(6):1543-9 discussion 1549-50.

[4] Eason E, Labrecque M, Marcoux S, Mondor M. Anal incontinence after childbirth. CMAJ 2002;166(3):326-30.

[5] Zetterstrom J, Lopez A, Anzen B, Norman M, Holmstrom B, Mellgren A. Anal sphincter tears at vaginal delivery: Risk factors and clinical outcome of primary repair. Obstet Gynecol 1999;94(1):21-8.

[6] Zetterstrom JP, Lopez A, Anzen B, Dolk A, Norman M, Mellgren A. Anal incontinence after vaginal delivery: A prospective study in primiparous women. Br J Obstet Gynaecol 1999;106(4):324-30.

[7] Abramowitz L, Sobhani I, Ganansia R, Vuagnat A, Benifla JL, Darai E, et al. Are sphincter defects the cause of anal incontinence after vaginal delivery? Results of a prospective study. Dis Colon Rectum 2000;43(5):590-6 discussion 596-8.

[8] Pollack J, Nordenstam J, Brismar S, Lopez A, Altman D, Zetterstrom J. Anal incontinence after vaginal delivery: A five-year prospective cohort study. Obstet Gynecol 2004;104(6):1397-402.

[9] Guise JM, Morris C, Osterweil P, Li H, Rosenberg D, Greenlick M. Incidence of fecal incontinence after childbirth. Obstet Gynecol 2007;109(2 pt 1):281-8.

[10] MacArthur C, Glazener CM, Wilson PD, Herbison GP, Gee H, Lang GD, et al Obstetric practice and faecal incontinence three months after delivery. BJOG $2001 ; 108(7): 678-83$.

[11] Sultan AH, Kamm MA, Hudson CN, Thomas JM, Bartram Cl. Anal-sphincter disruption during vaginal delivery. N Engl J Med 1993;329(26):1905-11.

[12] Borello-France D, Burgio KL, Richter HE, Zyczynski H, Fitzgerald MP, Whitehead W, et al. Fecal and urinary incontinence in primiparous women. Obstet Gynecol 2006;108(4):863-72.

[13] Chaliha C, Sultan AH, Bland JM, Monga AK, Stanton SL. Anal function: effect of pregnancy and delivery. Am J Obstet Gynecol 2001;185(2):427-32.

[14] Bo K, Owe KM, Nystad W. Which women do pelvic floor muscle exercises six months' postpartum? Am J Obstet Gynecol 2007;197(1) 49.e1-5.

[15] Sampselle CM. Changes in pelvic muscle strength and stress urinary incontinence associated with childbirth. J Obstet Gynecol Neonatal Nurs 1990;19(5):371-7. 